\title{
Alternative Energy Sources and Energy Infrastructure for Dutch Greenhouses - Investigating Growers' Preferences
}

\author{
Yashar Araghi and Gerard P.J. Dijkema \\ Energy and Industry group, Faculty of Technology Policy and Management, Delft University of Technology, The Netherlands
}

\section{INTRODUCTION}

Growing plants, vegetables and flowers in greenhouses constitutes the core business and capability of the Dutch horticulture industry. Greenhouse owners in the Netherlands use advanced technology to maintain the quality of products and to remain competitive in international markets despite high cost of labour and energy.

Today, Dutch greenhouse growers mainly depend on natural gas for heating their greenhouses. Next to boilers, many units of combined heat and power (CHP) have been installed over the last decade which deliver heat, produce electricity and even $\mathrm{CO}_{2}$ for more efficient crop harvesting. However, the sector has come to realize that, in foreseeable future, they need to switch to other energy sources to secure their energy supply and increase the sustainability of their business for reasons of depleting natural gas, and fierce market competition.

The sunk investments in energy technology are enormous and largely depend on regional energy infrastructure for gas, electricity, heat and $\mathrm{CO}_{2}$. Furthermore, growers are exposed to gas, electricity and $\mathrm{CO}_{2}$ markets and must face their rising prices. Adopting alternative sources and technologies requires substantial investment and carries substantial risk. All these considerations make the decision process to adopt new energy source a complicated and fuzzy one.

In this study, we investigate growers' preferences and opinions regarding three potential alternative energy sources and associated technologies: solar thermal energy, geothermal energy and biogas.

We use established methods from consumer behaviour theory and choice-modelling to elucidate how growers form an opinion and decide on the next technology to employ and grow their business.

Keywords: Greenhouse, Alternative Energy, Choice modelling, Stated Preferences, Attitudes

\section{BACKGROUND}

In a greenhouse, a protected micro-climate is created and maintained. In the early 20th century, heating already was used to warm greenhouses in early spring and to secure crops from late frost. Following the availability of natural gas, from the seventies central-heating systems have been installed on a large scale, which allowed many growers to adopt a cultivation season that runs from February till November, depending on the crop grown.

A greenhouse is also a giant collector of solar heat, which over a year accumulates far more energy than required to maintain temperature. In current greenhouse designs, however, on hot days the surplus heat is released by ventilation, while on moderate and cold days, the central heating is switched on. As a consequence, currently, in the Netherlands, 
greenhouses consume large amount of energy, which is equivalent to $7 \%$ of total national consumption ${ }^{1}$ from conventional sources, mainly from natural gas. Thus the horticultural industry has become highly dependent on secure, affordable energy to remain competitive. This emphasises the sensitive role of energy infrastructure - the natural gas network, the electricity grid, and increasingly local or regional $\mathrm{CO}_{2}$, heat or biogas grids play in the horticulture industry. Individual growers and sector organizations have recognized this situation, and developed strategies to deal with the problem of high energy dependence of greenhouses by new greenhouse designs such as the "closed greenhouse" concepts or the "energy-producing greenhouse" (Kas als Energiebron) systems. Some greenhouse companies, based on scientific studies and support from research centres, have invested in geothermal heat sources and infrastructure for seasonal heat storage and heat distribution.

Meanwhile, the Dutch government has supported improving sustainability and efficiency in the greenhouse sector notably through the agreement called the GLAMI covenant ${ }^{2}$. This agreement sets out number of targets, and stipulates that among others, energy efficiency and sustainable energy sources are discussed. In terms of efficiency, the greenhouse sector has been quite successful, thanks to the rapid adoption of CHP technology, where natural gas is consumed to produce heat, electricity and $\mathrm{CO}_{2}$ for cultivation ${ }^{3}$. With the $\mathrm{CHP}$ technology and energy conservation innovations and new isolation methods implemented in the greenhouses, the sector has been able to reduce energy consumption by 53\% in 2010 compared to the amount used in 1990. Consequently, the $\mathrm{CO}_{2}$ emissions were reduced by more than the amount expected in the GLAMI. However, with respect to sustainability the sector has not been so successful. From 4\% target for using sustainable energy sources (as mentioned in the Agro covenant) only $1.6 \%$ was reached by the sector in 2010. Currently more than 18 percentage points are required to reach the $20 \%$ projected targets for year $2020^{4}$.

One of the underlying reasons for not achieving the sustainability target can be related to the wide adoption of CHP technology in the sector. Since year 2003, the availability of CHP technology together with the liberalization of the electricity market allowed growers to obtain extra revenues by delivering excess electricity to the grid. Growers could shift their electricity load to periods with high spot market prices, which led many grower to adopt CHP technology ${ }^{5}$. The rapid uptake of CHP technology in the sector, due to its clear financial benefits ${ }^{3}$, has out competed other potential and sustainable energy sources. This resulted in the sector not realizing the targets set for using sustainable energy sources.

$\mathrm{CHP}$ technology consumes large quantities of natural gas, which is not considered to be a sustainable source of energy. Furthermore it has been recognized that natural gas dependency translates into vulnerability for a number of reasons: depleting national resources, the problem of security of supply from exporting countries, and increasing (or at least variable or unpredictable) prices. Furthermore, some growers have realized that "sustainably grown crop" is a label that may distinguish their product and bring in higher revenue. As a consequence, both the sector and government are actively seeking to promote and accomplish an "energy transition" of the sector.

\section{AlM}

The energy-related literature in horticulture research has mainly contributed towards proposing new design methods in cultivation to reduce energy demands ${ }^{6}$, produce less emissions ${ }^{7}$ or to build the structure with such materials that minimize heat loss from the greenhouse ${ }^{8}$. Some literature has explored new energy sources and the economic potential

1 Aramyan, L. H., Lansink, A. G. O., Van Der Vorst, J. G., \& Van Kooten, O. (2007). Performance measurement in agri-food supply chains: a case study. Supply Chain Management: An International Journal, 12(4), 304-315.

2 Breukers, A., 2008. The power of Dutch greenhouse vegetable horticulture. LEI Wageningen UR, The Hague

3 Compernolle, T., Witters, N., Van Passel, S., \& Thewys, T. (2011). Analyzing a self-managed CHP system for greenhouse cultivation as a profitable way to reduce $\mathrm{CO}<\mathrm{sub}>2</$ sub>-emissions. Energy, 36(4), 1940-1947.

4 van der Velden, N. J. A., \& Smit, P. X. (2013). Energiemonitor van de Nederlandse glastuinbouw 2012. LEI Wageningen UR.

5 Vermeulen, P. C. M., \& van der Lans, C. J. M. (2010, October). Combined Heat and Power (CHP) as a Possible Method for Reduction of the $\mathrm{CO}_{2}$ Footprint of Organic Greenhouse Horticulture. In I International Conference on Organic Greenhouse Horticulture 915 (pp. $61-68$ ).

6 Zwart, H. F. D. (1996). Analyzing energy-saving options in greenhouse cultivation using a simulation model (Doctoral dissertation, Landbouwuniversitet te Wageningen).

7 van't Ooster, A., Van leperen, W., \& Kalaitzoglou, P. (2010, August). Model study on applicability of a semi closed greenhouse concept in Almeria: effects on greenhouse climate, crop yield and resource use efficiency. In XXVIII International Horticultural Congress on Science and Horticulture for People (IHC2010): International Symposium on 927 (pp. 51-58).

8 Vanthoor, B. H. E., Stanghellini, C., Van Henten, E. J., \& De Visser, P. H. B. (2011). A methodology for model-based greenhouse design: 
of harvesting them for commercial cultivation ${ }^{4}$. In retrospect surprisingly, a survey of some Dutch firms (including a few horticulture related firms) found that energy-saving investment decisions will not have a significant impact on profitability and competitive position of the firms ${ }^{9}$. Meanwhile, to the best of our knowledge, the views and opinions of growers, who are often the main investors and adopters of new technologies in horticulture industry, have not yet been investigated. Therefore, in this study we will focus on growers and their decision-making.

Greenhouse growers have an entrepreneurial attitude and are involved in tight competition in the vegetables and flowers sector ${ }^{10}$. They are mostly pro- innovation professionals and capable of assessing different proposed measures ${ }^{11}$. In the past few years, the three energy sources proposed (i.e. solar thermal energy, geothermal energy and biogas ) have been installed and tested in a small number of greenhouses in the Netherlands. Through educational gatherings and symposiums (e.g. EnergieK2020 event organised by initiative called: KasalsEnergiebron), experts have revealed practical examples of these alternative sources being applied to different greenhouses and demonstrated to growers that such sources can provide full or partial substitutes for natural gas.

Based on known characteristics about growers, in this research we conduct a survey on them to gather their state-ofmind and their judgement as a hypothetical investor on the alternative energy sources/technologies proposed. We set up a stated-choice experiment among a sample of Dutch growers, where we ask their opinions and their preferences about the three alternative energy sources and their willingness to adopt such innovative measures in the (near) future. The experiment consists of offering different scenarios to growers and asking them to select the most desired alternative energy based on their attributes. Furthermore, we ask about growers' attitudes on environmental matters and on pollution emitted from their greenhouse when burning fossil fuels. We jointly analyse growers' choices on alternatives and their attitudes on emissions to the environment, to infer a deeper understanding of their opinions and preferences.

The societal contribution of this work is that these findings can contribute to our understanding of the relationship between people's attitudes and stated preferences regarding environmental values and policies. At a practical level, this work provides some recommendations to the governing bodies to implement tailored policies that aim to steer different sectors in the horticulture industry towards a more environmental and sustainable way of growing their crops.

\section{METHOD}

The main method used, in this research, to estimate preferences of growers is based on Discrete Choice Models (DCM), which has been introduced by McFadden in 1974. These models have been used to explain preferences of individuals and predict market shares for products and services in many domains such as transportation, health care, consumer choice, and environmental economics ${ }^{12}$. With the information obtained from choice experiments, one can estimate coefficients that quantitatively describe the importance of different attributes to individuals (i.e. growers).

In choice models, the analyst represents the decision making procedure of people as a utility maximization exercise, whereby each individual tries to maximize his/her utility from the alternative options that are offered to him/her. This is based on random utility theory where individual i gains utility $U$ from each alternative option e, shown as: . The utility is further defined as: , where the first part is the deterministic part, which is calculated from the choices that individuals make when observing the available sets of alternatives and where is the vector of coe cients, and is a vector of alternatives. The is the random component, which is assumed to be identically distributed extreme values [type I extreme value] ${ }^{13}$.

During the design of a choice experiment, several choice sets are created. In each choice set, constant numbers of alternatives (i.e. profiles of energy sources) with different values for each attribute are listed. The three alternatives were three energy sources: solar thermal energy, biofuel based energy, geothermal energy. Four constant attributes have been considered for each alternative; however, the specific values for attributes are varied. Table 1 shows the alternatives and attributes that are considered for this study and the range for each attribute are given on this table.

\footnotetext{
Part 1, a greenhouse climate model for a broad range of designs and climates. Biosystems Engineering, $110(4), 363-377$.

9 De Groot, H. L., Verhoef, E. T., \& Nijkamp, P. (2001). Energy saving by firms: decision-making, barriers and policies. Energy Economics, 23(6), 717-740

10 van der Veen, R., 2012. Case study 'CHP diffusion in Dutch greenhouses'. Final report, Delft University of Technology, faculty of Technology Policy and Management.

11 Schrauwen, N. (2012). Innovativeness of innovation (Doctoral dissertation, Master's thesis, TU Delft. 167).

12 Chorus, C. G. (2012). Random Regret-based discrete choice modelling: A tutorial. Springer.

13 Train, K. (2009). Discrete choice methods with simulation. Cambridge university press.
} 


\begin{tabular}{|c|c|c|c|}
\hline Alternatives & Solar thermal energy & Bio-fuel energy & Geothermal energy \\
\hline Beginning investment $/ \mathrm{m}^{2}$ & $65-80 € / \mathrm{m}^{2}$ & $20-25 € / \mathrm{m}^{2}$ & $80-200 / \mathrm{m}^{2}$ \\
\hline $\begin{array}{l}\text { Amount of natural gas saved }\left[\mathrm{m}^{3} \text { a.e. }\right. \\
\left./\left(\mathrm{m}^{2} \mathrm{jr}\right)\right]^{\star}\end{array}$ & $\begin{array}{c}10-11 \\
{\left[\mathrm{~m}^{3} \text { a.e. } /\left(\mathrm{m}^{2} \mathrm{jr}\right)\right]}\end{array}$ & $\begin{array}{c}\text { 8-13 } \\
{\left[\mathrm{m}^{3} \text { a.e. } /\left(\mathrm{m}^{2} \mathrm{jr}\right)\right]}\end{array}$ & $\begin{array}{c}21-40-120 \\
{\left[\mathrm{~m}^{3} \text { a.e. } /\left(\mathrm{m}^{2} \mathrm{jr}\right)\right]}\end{array}$ \\
\hline Additional electricity required $\left(\mathrm{kWh} / \mathrm{m}^{2}\right)$ & $25-27 \mathrm{kWh} / \mathrm{m}^{2}$ & $2-3 \mathrm{kWh} / \mathrm{m}^{2}$ & $7-11 \mathrm{kWh} / \mathrm{m}^{2}$ \\
\hline Emission savings (gr/m²) & $6-7 \mathrm{gr} / \mathrm{m}^{2}$ & $22-31 \mathrm{gr} / \mathrm{m}^{2}$ & $32-66 \mathrm{gr} / \mathrm{m}^{2}$ \\
\hline
\end{tabular}

* cubic meters of natural gas saved per meter squared of greenhouse in duration of one year

The choice experiment is implemented in the form of a survey. In our study, the survey is performed in two ways: 1) an online questionnaire with the web-link sent to email addresses of growers and 2) face-to-face interviews with growers who participated in a horticulture-related trade exhibition.

The survey has three distinct parts. The first part of the survey collects some demographic information from growers and some questions about current crop cultivated, energy source and other information about the type of greenhouse. The objective of this part is to check for the representativeness of growers in the sample. The second part of survey collects the preferences of growers from the alternative energy sources offered in several choice sets; the third part asks questions about growers' attitudes related to pollution caused by cultivation. The number of choice sets given to each respondent is constant and it is determined during the design of the choice experiment based on the number of selected alternatives, numbers of attributes defined and the levels attached to attributes. Table 2 shows an example choice set as seen by respondents (the English translated version).

\section{Table 2 An example choice set}

\begin{tabular}{|l|c|c|c|} 
& Solar thermal energy & Bio-fuel energy & Geothermal energy \\
\hline Beginning investment $€ / \mathrm{m}^{2}$ & $65 € / \mathrm{m}^{2}$ & $21 € / \mathrm{m}^{2}$ & $150 € / \mathrm{m}^{2}$ \\
\hline $\begin{array}{l}\text { Amount of natural gas saved }\left[\mathrm{m}^{3} \text { a.e./ }\right. \\
\left.\left(\mathrm{m}^{2} \mathrm{jr}\right)\right]\end{array}$ & $10\left[\mathrm{~m}^{3} \mathrm{a} . \mathrm{e} . /\left(\mathrm{m}^{2} \mathrm{jr}\right)\right]$ & $12\left[\mathrm{~m}^{3} \mathrm{a} . \mathrm{e} . /\left(\mathrm{m}^{2} \mathrm{jr}\right)\right]$ & $40\left[\mathrm{~m}^{3}\right.$ a.e. $\left./\left(\mathrm{m}^{2} \mathrm{jr}\right)\right]$ \\
\hline $\begin{array}{l}\text { Additional electricity required } \\
\left(\mathrm{kWh} / \mathrm{m}^{2}\right)\end{array}$ & $27 \mathrm{kWh} / \mathrm{m}^{2}$ & $3 \mathrm{kWh} / \mathrm{m}^{2}$ & $10 \mathrm{kWh} / \mathrm{m}^{2}$ \\
\hline Emission savings (gr/m $\left.{ }^{2}\right)$ & $7 \mathrm{gr} / \mathrm{m}^{2}$ & $31 \mathrm{gr} / \mathrm{m}^{2}$ & $55 \mathrm{gr} / \mathrm{m}^{2}$ \\
\hline Which Energy source do you prefer? & & & \\
\hline
\end{tabular}

Once the survey is completed by a sufficient number of respondents, statistical models such as Multi-Nomial Logit $(\mathrm{MNL})$ are used to estimate growers' preference by calculating parametric coefficients. These coefficients tell us which alternative is most desirable and which attribute has most impact on the growers' total utility function (the effects of the attributes are assumed to be linear). A software package called BIOGEME is used to calculate the coefficients of different attributes based on MNL model from the choice data ${ }^{14}$. The values of these coefficients indicate the slope of utility curve. The MNL is selected based on the assumption that the utility as obtained from the choices of respondents is composed of a systematic non-random part (also known as observed part of utility) and a random error part. The other assumption was that the additional random error term would be independently and identically distributed (IID) ${ }^{15}$.

14 Bierlaire, M. (2003). BIOGEME: A free package for the estimation of discrete choice models, Proceedings of the 3rd Swiss Transportation Research Conference, Ascona, Switzerland.

15 Hensher, D. A., Rose, J. M., \& Greene, W. H. (2005). Applied choice analysis: a primer. Cambridge University Press. 
The idea of choice-modelling is that, while growers choose among energy alternatives, they implicitly revealed their preferences on the alternatives and attractiveness of the attributes. Furthermore, based on growers' background characteristics and the type of horticulture, they can be clustered into groups that have common characteristics. Distinct utility functions are calculated for each cluster and hence the heterogeneity among different type of growers is investigated.

\section{RESULTS}

Although the online survey is still ongoing and more data from growers are expected, we are able to provide some preliminary results based on data already gathered from growers. The most influential attribute on growers opinions is the "amount of natural gas saved" per energy resource, whereas, our intuition was that "beginning capital" would be most influential attribute. The latter attribute came only as second most influential attribute. Emission savings appear to be the attribute least important to the growers.

Those respondents that grew crops with intensive heat demand (e.g. tropical pot plants) even put more emphasis on the quantity of natural gas saved per meter squared in a year. In contrast, those growers who require a lot of lighting in their cultivation process were more concerned with the "additional electricity required" attribute.

With this type of analysis, it is revealed that different solutions are preferred for different types of cultivations. For instance, those growers with intensive heat requirements for their crops are more inclined to invest on geothermal energy, whereas those who required more light in their greenhouses are willing to invest in a biofuel alternative (in comparison to the rest of the growers). The reason behind this behaviour is that with investing in biofuels, these growers do not need to buy a large quantity of electricity from the grid, which will reduce their production costs.

At a more abstract level and when considering alternatives, the geothermal energy has been chosen as most favourite alternative amongst the three alternatives for delivering a high quantity of heat and for requiring less electricity usage, while this source of energy also provides the highest emission savings among the alternatives.

\section{CONCLUSION}

This research employs a proven methodology called discrete choice modelling and applies it in the field of horticultural research. The opinion and preferences of greenhouse growers are investigated regarding use of alternative energy sources in Dutch greenhouses. Also the attitude of these growers with respect to emissions from burning natural gas are measured and reflected in their choices. The most important aspect relating to energy use in greenhouses are thought to be heat, electricity and initial investment on new energy sources.

Different types of crops dominate preferences of growers and their approaches towards the issue of energy alternatives. In the absence of fossil fuels, if the crop requires a large amount of heat, then growers are more interested in geothermal energy and if the crops require electricity for lighting then growers tend to go for bio-fuels. These findings capture the mind-set of growers and their probable approach towards the introduction of alternative and sustainable energy sources, given that fossil fuels become scares or too expensive.

Furthermore, the outcomes of this research can be helpful for infrastructure decision makers and planners. The results confirm that different sort of cultivations have different utility requirements. Therefore, the decision to provide heat, electricity or $\mathrm{CO}_{2}$ for horticultures can be based on the type of crops that are cultivated in a given area. Also in this research we intend to provide policy recommendations to further guide/steer Dutch greenhouse growers to move towards alternative and sustainable energy sources, and thus help shape their energy transition.

\section{ACKNOWLEDGEMENT}

This work has been funded in part by the European Regional Development Fund, program Duurzame Greenport Westland-Oostland (http://www.greenportduurzaam.nl). 